Proyecciones

Vol. $12 \mathrm{~N}^{0} 2$, pp.119-128 December 1993

Universidad Católica del Norte

Antofagasta - Chile

\title{
RESULTS ON THE CHEBYSHEV METHOD IN BANACH SPACES
}

\author{
I.K. ARGYROS \\ Cameron University, Oklahoma, USA. \\ DONG CHEN \\ University of Arkansas, Arkansas, USA.
}

\begin{abstract}
In this paper, under standard Newton-Kantorovich conditions, we establish the Kantorovich-type convergence theorem for Chebyshev method in Banach spaces.
\end{abstract}

Key words: Numerical Solutions of Nonlinear operator equations, Banach spaces, Chebyshev iterative method, Kantorovich-type convergence, Newton-Kantorovich assumptions, Error bound expression.

AMS(MOS) Classification: $65 \mathrm{H} 10,65 \mathrm{~J} 15,47 \mathrm{H} 17$ 


\section{Introduction.}

In this study we are concerned with the problem of approximating a locally unique solutions $x^{*}$ of the equation

$$
F(x)=0
$$

in Banach space $X$, where $F$ is a nonlinear operator defined on some convex subset $D$ of $X$ with values in a Banach space $Y$. Let $x_{0} \in D$ and define the Chebyshev method for all $n \geq 0$ by

$$
y_{n}=x_{n}-F^{\prime}\left(x_{n}\right)^{-1} F\left(x_{n}\right)
$$

$$
x_{n+1}=y_{n}-\frac{1}{2} F^{\prime}\left(x_{n}\right)^{-1} F^{\prime \prime}\left(x_{n}\right)\left(y_{n}-x_{n}\right)^{2}
$$

Here $F^{\prime}\left(x_{n}\right)$ and $F^{\prime \prime}\left(x_{n}\right)$ denote the first and second Frechet derivatives of $F$ evaluated at $x=x_{n}$. Note that $F^{\prime}\left(x_{n}\right)$ is a linear operator whereas $F^{\prime \prime}\left(x_{n}\right)$ is a bilinear operator for all $n \geq 0$ [1], [2]. If the sequences $\left\{x_{n}\right\}$ defined by (2) and (3) converges to a limit $x^{*} \in D$, then $x^{*}$ is a zero of equation (1). The convergence analysis for the Chebyshev method has been well stablished in $C$ [3]. Our convergence analysis will be carried out in a Banach space setting. We will show that under standard Newton-Kantorovich assumptions [4-8] the Chebyshev method converges faster to a zero $x^{*}$ of equation (1) than Newton's method.

\section{Convergence Analysis.}

We will first need the following results:

Lemma 2.1. Let $F: D \subset X \longrightarrow Y$. Assume

a) The nonlinear operator $F$ is twice Frechet differentiable on the $D$.

b) The iterates $x_{n}$ generated by (2) and (3) belong in $D$ and $F^{\prime}\left(x_{n}\right)^{-1}$ exist for all $n \geq 0$. 
Then the following approximation is true for all $n \geq 0$ :

$$
\begin{aligned}
F\left(x_{n+1}\right)=\int_{0}^{1} F^{\prime \prime}\left[y_{n}+t\left(x_{n+1}-y_{n}\right)\right](1-t) d t\left(x_{n+1}-y_{n}\right)^{2} \\
-\frac{1}{2} \int_{0}^{1} F^{\prime \prime}\left[x_{n}+t\left(y_{n}-x_{n}\right)\right]\left(y_{n}-x_{n}\right) F^{\prime}\left(x_{n}\right)^{-1} F^{\prime \prime}\left(x_{n}\right)\left(y_{n}-x_{n}\right)^{2} \\
+\int_{0}^{1}\left\{F^{\prime \prime}\left[x_{n}+t\left(y_{n}-x_{n}\right)\right](1-t)-\frac{1}{2} F^{\prime \prime}\left(x_{n}\right)\right\} d t\left(y_{n}-x_{n}\right)^{2} .
\end{aligned}
$$

Theorem 2.1. Let $F: D \subset X \longrightarrow Y, X$ and $Y$ are real Banach spaces, and $\mathrm{D}$ is an open convex domain. Assume that $\mathrm{F}$ has $2 \mathrm{nd}$ order continuous Frechet derivatives on $D$ and for given an initial value $x_{0} \in D$ that the following standard Newton-Kantorovich conditions are satisfied:

$$
\left\|F^{\prime \prime}(x)\right\| \leq M,\left\|F^{\prime \prime}(x)-F^{\prime \prime}(y)\right\| \leq N\|x-y\|,
$$

$$
\left\|F^{\prime}\left(x_{0}\right)^{-1}\right\| \leq \beta,\left\|F^{\prime}\left(x_{0}\right)^{-1} F\left(x_{0}\right)\right\| \leq \eta,
$$

$$
M\left[1+\frac{N}{3 M^{2} \beta}\right]^{1 / 2} \leq K, h=K \beta \eta \leq 0.485,
$$

$$
\overline{U\left(x_{0}, t^{*}\right)} \subset D
$$

where $\overline{U(x, r)}=\left\{x^{\prime} \in x \mid\left\|x^{\prime}-x\right\| \leq r\right\}$, and

$$
g(t)=\frac{1}{2} K t^{2}-\frac{1}{\beta} t+\frac{\eta}{\beta},
$$

$$
t^{*}=\frac{1-\sqrt{1-2 h}}{h} \eta
$$

$$
t^{* *}=\frac{1+\sqrt{1-2 h}}{h} \eta
$$




$$
\theta=\frac{1-\sqrt{1-2 h}}{1+\sqrt{1-2 h}}
$$

where $t^{*}$ is the smallest root of equation (8). Then the iteration generated by (2) and (3) is well defined for all $n \geq 0$ and converges to zero $x^{*} \in U\left(x_{0}, t^{*}\right)$ of equation (1). Moreover $x_{n}, y_{n} \in \widehat{U\left(x_{0}, t^{*}\right)}$, for all $n \geq 0$. Furthermore the following error estimates are true for all $n \geq 0$.

$$
\left\|x_{n}-x^{*}\right\| \leq t^{*}-t_{n} \leq \frac{\left(1-\theta^{2}\right) \eta}{1-\frac{1}{\sqrt{2}}[\sqrt{2} \theta]^{3^{n}}}[\sqrt{2} \theta]^{3^{n}-1}
$$

where $\left\{t_{n}\right\}_{n=0}^{\infty}$ and $\left\{s_{n}\right\}_{n=0}^{\infty}$ are defined as

$$
\begin{gathered}
s_{n}=t_{n}-\frac{g\left(t_{n}\right)}{g^{\prime}\left(t_{n}\right)} \\
t_{n+1}=s_{n}-\frac{1}{2} \frac{g^{\prime \prime}\left(t_{n}\right)}{g^{\prime}\left(t_{n}\right)}\left(s_{n}-t_{n}\right)^{2} .
\end{gathered}
$$

Proof. It suffices to show that the following items are true for all $n$ by mathematical induction.

$\left(I_{n}\right):$

$$
x_{n} \in \overline{U\left(x_{0}, t_{n}\right)}
$$

$\left(I I_{n}\right):$

$$
\left\|F^{\prime}\left(x_{n}\right)^{-1}\right\| \leq-g^{\prime}\left(t_{n}\right)^{-1}
$$

$\left(I I I_{n}\right):$

$$
\left\|y_{n}-x_{n}\right\| \leq s_{n}-t_{n}
$$

$\left(I V_{n}\right):$

$$
y_{n} \in \overline{U\left(x_{0}, s_{n}\right)}
$$

$\left(V_{n}\right):$

$$
\left\|x_{n+1}-y_{n}\right\| \leq t_{n+1}-s_{n} .
$$

It is easy to check the case when $n=0$ by the initial conditions. Now assume that the above statements are true for a fixed $n \geq 1$. 
$\left(I_{n+1}\right)$ :

$$
\begin{aligned}
\left\|x_{n+1}-x_{0}\right\| & \leq\left\|x_{n+1}-y_{n}\right\|+\left\|y_{n}-x_{n}\right\|+\left\|x_{n}-x_{0}\right\| \\
& \leq\left(t_{n+1}-s_{n}\right)+\left(s_{n}-t_{n}\right)+\left(t_{n}-t_{0}\right) \\
& =t_{n+1} .
\end{aligned}
$$

$\left(I I_{n+1}\right):$

$$
F^{\prime}\left(x_{n+1}\right)-F^{\prime}\left(x_{0}\right)=\int_{0}^{1} F^{\prime \prime}\left[x_{0}+t\left(x_{n+1}-x_{0}\right)\right] d t\left(x_{n+1}-x_{0}\right)
$$

so

$$
\begin{aligned}
\| F^{\prime}\left(x_{n+1}-F^{\prime}\left(x_{0}\right) \|\right. & \leq M\left\|x_{n+1}-x_{0}\right\| \\
& \leq K\left(t_{n+1}-t_{0}\right) \\
& =K t_{n+1} \\
& <K t^{*} \\
& =K \frac{1-\sqrt{1-2 h}}{h} \eta \\
& =K \frac{1-\sqrt{1-2 h}}{K \beta \eta} \eta \\
& =K \frac{1-\sqrt{1-2 h}}{\beta} \\
& \leq \frac{1}{\beta} \\
& \leq \frac{1}{\left\|F^{\prime}\left(x_{0}\right)^{-1}\right\|},
\end{aligned}
$$


and by Banach lemma, $F^{\prime}\left(x_{n+1}\right)^{-1}$ exists and

$$
\begin{aligned}
\left\|F^{\prime}\left(x_{n+1}\right)^{-1}\right\| & \leq \frac{\left\|F\left(x_{0}\right)^{-1}\right\|}{1-\left\|F^{\prime}\left(x_{0}\right)^{-1}\right\|\left\|F^{\prime}\left(x_{n+1}\right)-F^{\prime}\left(x_{0}\right)\right\|} \\
& \leq \frac{\beta}{1-\beta K\left\|x_{n+1}-x_{0}\right\|} \\
& =\frac{1}{\frac{1}{\beta}-K\left\|x_{n+1}-x_{0}\right\|} \\
& \leq \frac{1}{\frac{1}{\beta}-K\left(t_{n+1}-t_{0}\right)} \\
& \leq \frac{1}{\frac{1}{\theta}-K t_{n+1}} \\
& =-g^{\prime}\left(t_{n+1}\right)^{-1} .
\end{aligned}
$$

$\left(I I I_{n+1}\right):$ By using the identity in the lemma 2.1, we can estimate $F\left(x_{n+1}\right)$ to obtain

$$
\begin{aligned}
\| F\left(x_{n+1}\right) & \leq \frac{M}{2}\left\|x_{n+1}-y_{n}\right\|^{2}+\frac{1}{2} \frac{M^{2}}{\frac{1}{\beta}-M\left\|x_{n}-x_{o}\right\|}\left\|y_{n}-x_{n}\right\|^{3}+\frac{N}{6}\left\|y_{n}-x_{n}\right\|^{3} \\
& \leq \frac{M}{2}\left\|x_{n+1}-y_{n}\right\|^{2}+\frac{\frac{M^{2}}{2}+\frac{N}{6 \beta}}{\frac{1}{\beta}-M\left\|x_{n}-x_{0}\right\|}\left\|y_{n}-x_{n}\right\|^{3} \\
& \leq \frac{K}{2}\left(t_{n+1}-s_{n}\right)^{2}+\frac{K^{2}\left(s_{n}-t_{n}\right)^{3}}{2\left(\frac{1}{\beta}-K t_{n}\right)} \\
& =g\left(t_{n+1}\right) .
\end{aligned}
$$

And so

$$
\begin{aligned}
\left\|y_{n+1}-x_{n+1}\right\| & =\left\|-F^{\prime}\left(x_{n+1}\right)^{-1}\right\|\left\|F\left(x_{n+1}\right)\right\| \\
& \leq\left\|F^{\prime}\left(x_{n+1}\right)^{-1}\right\|\left\|F\left(x_{n+1}\right)\right\| \\
& \leq-g^{\prime}\left(t_{n+1}\right)^{-1} g\left(t_{n+1}\right) \\
& =s_{n+1}-t_{n+1} .
\end{aligned}
$$


$\left(I V_{n+1}\right):$

$$
\begin{aligned}
\left\|y_{n+1}-x_{0}\right\| & \leq\left\|y_{n+1}-x_{n}\right\|+\left\|x_{n+1}-y_{n}\right\|+\left\|y_{n}-x_{n}\right\|+\left\|x_{n}-x_{0}\right\| \\
& \left.\leq\left(s_{n+1}-t_{n+1}\right)+\left(t_{n+1}-s_{n}\right)+\left(s_{n}-t_{n}\right)+t_{n}-t_{0}\right) \\
& =s_{n+1} .
\end{aligned}
$$

$\left(V_{n+1}\right):$ From (1), we have

$$
x_{n+2}-y_{n+1}=-\frac{1}{2} F^{\prime}\left(x_{n+1}\right)^{-1} F^{\prime \prime}\left(x_{n+1}\right)\left(y_{n+1}-x_{n+1}\right)^{2},
$$

and then

$$
\begin{aligned}
\left\|x_{n+2}-y_{n+1}\right\| & \leq\left\|-\frac{1}{2} F^{\prime}\left(x_{n+1}\right)^{-1}\right\|\left\|F^{\prime \prime}\left(x_{n+1}\right)\right\|\left\|y_{n+1}-x_{n+1}\right\|^{2} \\
& \leq-\frac{1}{2} g^{\prime}\left(t_{n+1}\right)^{-1} g^{\prime \prime}\left(t_{n+1}\right)\left(s_{n+1}-t_{n+1}\right)^{2} \\
& =t_{n+2}-s_{n+1} .
\end{aligned}
$$

Now we are ready to derive the error bound (12). Notice

$$
g\left(t_{n}\right)=\frac{K}{2}\left(t^{*}-t_{n}\right)\left(t^{* *}-t_{n}\right)
$$

and

$$
g^{\prime}\left(t_{n}\right)=-\frac{K}{2}\left[\left(t^{*}-t_{n}\right)+\left(t^{* *}-t_{n}\right)\right],
$$

it is simple calculus to show that

$$
\frac{t^{*}-t_{n}}{t^{* *}-t_{n}}=\left[\frac{t^{*}-t_{n-1}}{t^{* *}-t_{n-1}}\right]^{3} \frac{\left[\left(t^{*}-t_{n-1}\right)+2\left(t^{* *}-t_{n-1}\right)\right]}{\left[2\left(t^{*}-t_{n-1}\right)+\left(t^{* *}-t_{n-1}\right)\right]}
$$

Now since $0 \leq \frac{t^{*}-t_{n-1}}{t^{* *}-t_{n-1}} \leq 1$, we obtain

$$
\frac{t^{*}-t_{n}}{t^{* *}-t_{n}} \leq 2\left[\frac{t^{*}-t_{n-1}}{t^{* *}-t_{n-1}}\right]^{3}
$$

the estimate (12) now follows from the equalities $t^{*}=(1+\theta) \eta$, and $t^{* *}=$ $t^{*}+\frac{\left(1-\theta^{2}\right) \eta}{\theta}$. That completes the proof of the theorem. 
Remark. From liypotheses (5) and estimate

$$
\begin{aligned}
&\left\|F^{\prime}\left(x_{0}\right)^{-1}\right\| \int_{0}^{1}\left\|F^{\prime}\left(x^{*}+t\left(y^{*}-x^{*}\right)\right)-F^{\prime}\left(x_{0}\right)\right\| d t \leq \beta \int_{x_{0}}^{x^{*}+t\left(y^{*}-x^{*}\right)}\left\|F^{\prime \prime}(z)\right\|\|d z\| \\
& \leq \beta M \int_{0}^{1}\left\|x^{*}+t\left(y^{*}-x^{*}\right)-x_{0}\right\| d t \\
& \leq \beta M \int_{0}^{1}\left[(1-t)\left\|x^{*}-x_{0}\right\|+t\left(y^{*}-x_{0}\right) \|\right] d t \\
& \leq \beta M t^{*} \\
&<1 .
\end{aligned}
$$

Hence the linear operator $\int_{0}^{1} F^{\prime}\left(x^{*}+t\left(y^{*}-x^{*}\right)\right) d t$ is invertible. Consequently, if $y^{*}$ is a second of the equation (1) in $U\left(x_{0}, t^{*}\right)$, it follows from the approximation

$$
\int_{0}^{1} F^{\prime}\left(x^{*}+t\left(y^{*}-x^{*}\right)\right) d t\left(y^{*}-x^{*}\right)=F\left(y^{*}\right)-F\left(x^{*}\right)=0 .
$$

That $x^{*}=y^{*}$. Therefore under the hypotheses of the theorem the uniqueness of the solution $x^{*}$ of equation (1) in $U\left(x_{0}, t^{*}\right)$ has been established.

\section{Applications.}

In this section, we use the Theorem 2.1 to suggest some new approaches to the solution of quadratic integral equations of the forms:

$$
x(s)=y(s)+\alpha x(s) \int_{0}^{1} q(s, t) x(t) d t
$$

in the space $X=C[0,1]$ of all continuous functions on the interval $[0,1]$ with the norm

$$
\|x\|=\max _{0 \leq s \leq 1}|x(s)|
$$

Here we assume that $\alpha$ is a real number called the "albedo" for scattering and the kernal $q(s, t)$ is a continuous function of two variables with $0 \leq s, t \leq 1$ 
and satisfying

$$
\begin{gathered}
0<q(s, t)<1, \quad 0 \leq s, t \leq 1, \\
q(s, t)+q(t, s)=1, \quad 0 \leq s, t \leq 1 .
\end{gathered}
$$

The function $y(s)$ is given by a continuous function defined on $[0,1]$, and $x(s)$ is the unknown function sought in $[0,1]$. Equations of this type are related with the work of $S$. Chandrasokhar [1.2], and arise in the theories of radiative transfer, neutron transport and in the kinetic theory of gasses. There exists an extensive literature on equations like (15) under various assumptions on the kernel $q(s, t)$ and $\alpha$ is a real or complex number. One can refer to the recent work in $[1,2]$ and the references there. Here we demonstrate that the theorem via the iterative procedures (2) and (3) provide existence results for (15). Moreover, the iterative procedures (2) and (3) converge faster than the solution of all the previous known ones. Furthermore, a better information on the location of the solution is given. Note that the cost is not higher than the corresponding one of previous methods. For simplicity, we shall assume that

$$
q(s, t)=\frac{s}{s+t}, 0 \leq s, t \leq 1
$$

Notice that $q(s, t)$ satisfies (17) and (18) above. Let us now choose $y(s)=1$ for all $s$ in $[0,1]$ and define the operator $F$ on $X=C[0,1]$ by

$$
F(x)=\alpha x(s) \int_{0}^{1} \frac{s}{s+t} x(t) d t-x(s)+1
$$

Note that every root of the equation $F(x)=0$ satisfies the equation (15). Set $x_{0}(s)=1$ and $\alpha=0.25$, use the definition of the first and second Frechet derivatives of the operator $F$ to obtain

$$
\begin{gathered}
M=2|\alpha| \max _{0 \leq s \leq 1}\left|\int_{0}^{1} \frac{s}{s+t} d t\right|=(2 \ln 2)|\alpha|=0.34657359 \\
N=0, K=M, \beta\left\|F^{\prime}(1)^{-1}\right\|=1.53039421 \\
t^{*}=0.28704852, \theta=0.08239685
\end{gathered}
$$

and

$$
\left\|x_{n}-x^{*}\right\| \leq \frac{\left(1-\theta^{2}\right) \eta}{1-\frac{1}{\sqrt{2}}[\sqrt{2} \theta]^{3^{n}}}[\sqrt{2} \theta]^{3^{n}-1}
$$




$$
=\frac{0.26339662}{1-\frac{1}{\sqrt{2}}(0.116526742)^{3^{n}}}(0.116526742)^{3^{n}-1}
$$

for all $n \geq 0$, which shows that $x^{*}$ is unique in $U\left(x_{0}, t^{*}\right)$.

\section{REFEREN CES}

[1] Argyros, I.K.: Quadratic equations and applications to Chandrasekliar's and related equations. Bull. Austral. Math. Soc., 32 (1988), 275-292.

[2] Argyros, I.K.: On a class of nonlinear integral equations arising in Neutron Transport. Aequations Mathematicae, 36 (1988), 99-111.

[3] Chell, D.: Standard Kantorovich theorem of the Chebyshev method on complex plane. Intern. J. Computer Math., 42:(1+2) (1993), 67-70.

[4] Gragg, W.B.; Tapia, R.A.: Optimal error bounds for Newton-Kantorovich Theorem. SIAM J. Numer. Anal, 11 (1974), 10-13.

[5] Kantorovicl, L.V.; Akilov, G.P.: Functional Analysis in Normed Spaces. Pergamon Press, New York, 1964.

[6] Ostrowski, A.M.: Solution of Equations in Euclidean and Banach Spaces. Academic Press, New York, 3rd ed., 1973.

[7] Rall, L.B.: Computational Solution of Nonlinear Operator Equations. John Wiley 6 sons, Inc., New York, 1969.

[8] Yamamoto, T.: On the methos of Tangent Hyperbolas in Banach Spaces. J. Computational and Applied Math., 21(1988), 75-88.

Received: December 10, 1992.

\section{I.K. Argyros}

Department of Mathematics

Cameron University

Lawton, Oklahoma 73505, USA.

Dong Chen

Department of Mathematical Sciences

University of Arkansas

Fayetteville, Arkansas 72701, USA. 